\title{
Analysis of Vegetable Marketing Efficiency in Phek District, Nagaland
}

\author{
Praveen Dukpa* and T. Zarenthung Ezung \\ Department of Economics, Nagaland University, Lumami \\ *Corresponding author: praveenptrck5@gmail.com (ORCID ID: 0000-0003-2663-6202)
}

Received: $02-04-2020$

Revised: 08-07-2020

Accepted: 20-08-2020

\begin{abstract}
Vegetables are an integral part of the human daily diet; it also plays a vital role in the contribution to the farmer's income and the National income. Thus, a study was carried out to analyse and find out the most efficient marketing system and channel using the Shepherds and Modified Acharya-Agarwal marketing efficiency method. The article is based on the study of 300 farmers from twelve villages in Phek district, which is well known for vegetable production and marketing in Nagaland. The marketing cost, price spread, net margins, etc. have been discussed under various channels. The vegetables selected for the study were Cabbage, Beans, and Potato. Numerous production and marketing constraints were also observed, and suggestive recommendations were made to increase production and marketing efficiency. Three marketing Channels were observed, and the most efficient marketing channel was found to be Channel I, where there is direct marketing between the Producer and the Consumer.
\end{abstract}

\section{Highlights}

( Vegetable Marketing efficiency in Phek District, Nagaland has been studied and analyzed using Shepherds and Modified Acharya-Agarwal marketing efficiency method.

Keywords: Vegetable marketing, Market efficiency, Nagaland

Vegetables are an indispensable component of the human diet around the globe, irrespective of race and religion, to live a healthy life. There is no denying the fact of the nutritional and health benefits of vegetable consumption. Consumption of vegetables provides all the essential nutrients, vitamins, dietary fibers, etc. required for a healthy body. In India production of vegetables has increased from 101.2 Million Tonnes to 184.40 Million Tonnes since 2004-05 to 2017-18 (NHB 2018). India produced 185.88 Million MT of vegetables in 2018-19 and is ranked second in the production of vegetables (NHB 2018-19). The advantage it possesses in the production of vegetables offers India a huge potential for export and revenue generation. During 2018-19, India exported vegetables worth ₹ 5419.48 crores 777.25 USD Millions. India is also the secondlargest Producer of Potato and Cabbage (Ramesh,
2017). The availability of vegetables in the markets depends on an efficient marketing system. Marketing of vegetables is a complex in itself due to its highly perishable in nature and bulkiness as such extra care and effort are needed for which it is necessary to know the most efficient marketing channel and system. An agricultural marketing system is said to be efficient if the farmers can dispose of their production at reasonable returns, which in turn raises the conditions and living standard of farmers and agriculture, which ultimately depends upon efficient agricultural marketing. An Efficient Agricultural marketing system is crucial for agricultural progress and development since it

How to cite this article: Dukpa, P. and Ezung, T.Z. (2020). Analysis of Vegetable Marketing Efficiency in Phek District, Nagaland. Economic Affairs, 65(3): 427-432.

Source of Support: None; Conflict of Interest: None

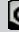


stimulates production, stables the output and prices. It also reduces costs of production, the producers get its due share and removes unfair Consumer's price. Without an efficient marketing system, agricultural development cannot progress and enhance production and price stability, which has been seen in many countries (Khalon and George, 1985).According to Prof. Faruque "Agricultural marketing involves all operations in the transfer of farm produce from the Producer to the final consumers. All operations such as collecting, grading, processing, preserving, transportation, and financing come under Agricultural marketing" (Dastagiri et al. 2013). Thus, Agricultural marketing can be defined as the study of all the activities, channels, cost etc., involved in the transfer of goods from the producer to the consumer. The agricultural marketing system act as a link between the farm and the non-farm sectors (Dastagiri et al. 2013). Horticultural goods require special care due to their nature of perishability and seasonality and are high capital and labour intensive. The farmers make a huge loss because they have to resort to distress sale due to the seasonality of vegetables which creates a market glut. The framers sell their produce to the contractors and commission agents. The price spread along the marketing channel is directly proportional to the number of market intermediaries involved along the (Gupta and Rathode, 1998). Thus, this article tries to highlight marketing of vegetable and its efficiency in Phek district, Nagaland during 2016-17 and to bring out suggestive measures and recommendations.

\section{METHODOLOGY}

Twelve villages from Phek District were chosen for the study based on their significance of vegetable production and marketing. The Villages chosen for the study were Enhulumi, Kami, Lasumi, Lekromi, Leshmi, Mesulumi, Pfutseromi, Razeba, Tsupfume, Zapami, Zelume and Zhavame. From twelve villages twenty five (25) random farmers cultivating the selected vegetables were taken for the study. Three Vegetable cabbage, beans and potato were selected for the study due to their significance in production and marketing in the Phek district. The primary data was collected through field survey and with a pre tested questionnaires and Secondary data from various published sources.
Shepherds Market Efficiency Method and AcharyaAgarwal modified method were used to analyse the vegetable marketing efficiency.

1. Shepherds Market Efficiency Method (Shepherd, 1965): The ratio of price paid by the consumer's (total value of goods) to total marketing cost is used as a measure of marketing efficiency.

$M E=\frac{V}{I}-1$

Where,

$M E$ = Marketing efficiency

$V=$ Price paid by consumer (value of goods purchased)

$I=$ Total Marketing Cost (Cost + margins)

2. Acharya- Agarwal modified method (Acharya and Agarwal, 2014): AcharyaAgarwal marketing measures include the total marketing cost, Net marketing margins, price received by farmer and price paid by the consumers.

$M M E=\frac{N P_{P}}{M C+M M}-1$

Where,

$M M E=$ Modified Measure of Marketing Efficiency

$N P_{P}=$ Net price received by the producer $(₹ / q)$

$M C=$ Marketing cost

$M M=$ Marketing margin

3. Marketable and Marketed surplus is estimated as:

Marketable Surplus $=$ Production - Total overall Consumption

Marketed surplus = Marketable SurplusTotal Post Harvest losses

\section{RESULTS AND DISCUSSION}

\section{Farm Size holding for Cultivation of Potato, Beans, Cabbage}

From the survey of 300 vegetable farmers cultivating Potato, Beans, and Cabbage, it was observed that the marginal farmers are dominant in all the three vegetables, which is shown in table 1 . Out of the 300 farmers taken for the study, none of the vegetable farmers were medium farmers 
cultivating in an area over 4 ha, which depicts the typical cultivation pattern of Indian and Nagaland cultivators cultivating in a small area. The marginal farmers dominates the production of vegetables since most the farm were fragmented only a few had a big farm size as such the small and semi-medium farmers were less in number. In the cultivation of Potato, $82.67 \%$ of the marginal were marginal farmers cultivating in a farm size less than 1 ha. Similarly, in the cultivation of Cabbage $85.67 \%$ of the farmers were marginal farmers, and 100\% of the farmers cultivating Beans were marginal farmers. The area under cultivation and production of Cabbage, Beans, and Potato in Phek district since 2008-09 to 2017-2018 of all three vegetables shows a positive correlation between the farm size and production.

Table 1: Percentage of farmers according to farm size

\begin{tabular}{llll}
\hline \multirow{2}{*}{$\begin{array}{l}\text { Size of the Holding } \\
\text { Potato }\end{array}$} & \multicolumn{2}{c}{$\begin{array}{c}\text { Percentage of farmers from } \\
\text { the sample villages number of } \\
\text { farmers }\end{array}$} \\
\cline { 2 - 4 } & \multicolumn{3}{c}{ Cabbage } \\
\hline Marginal (0Ha-1Ha) & $82.67 \%$ & $100 \%$ & $85.67 \%$ \\
Small (1Ha-2Ha) & $16 \%$ & 0 & $12.67 \%$ \\
Semi-medium (2Ha-4Ha) & $1.33 \%$ & 0 & $1.67 \%$ \\
Medium (4Ha-10Ha) & 0 & 0 & 0 \\
\hline Total & $\mathbf{1 0 0} \%$ & $\mathbf{1 0 0} \%$ & $\mathbf{1 0 0} \%$ \\
\hline
\end{tabular}

Sources: Field Survey 2016-2017.

\section{Marketed and Marketable Surplus}

Marketable surplus means the surplus with the farmers, which can be sold after the requirements of the farmers for consumption, for seed, for payment, etc. are met. On the other marketed surplus means the actual quantity of the produce which is sold by the farmers. The production, marketable, and marketed surplus of vegetables from the study area is shown in table 2 . The total production of Cabbage from the Study area was 25557.85 quintal, 289.76 quintal of Beans, and 1048.16 quintal of Potato. The production of Cabbage is higher than that of Beans and Potato. The marketable Surplus of Cabbage is $97.15 \%$ of the total production, which is comparatively higher than the Beans and Potato because Cabbage is cultivated with the primary objective of selling, unlike Beans, which is cultivated primarily for consumption and the surplus are disposed of for sale.
Table 2: Total Production, Marketable and Marketed Surplus in Phek district, Nagaland (2016-2017)

\begin{tabular}{llll}
\hline Particulars & Cabbage & Beans & Potato \\
\hline $\begin{array}{l}\text { Total production (in } \\
\text { Quintal) }\end{array}$ & 25557.85 & 289.76 & 1048.16 \\
Marketable surplus (in & 24828.50 & 162.87 & 810.65 \\
Quintal) & $(97.15 \%)$ & $(56.21 \%)$ & $(77.34 \%)$ \\
Marketed surplus (in & 24164.00 & 141.76 & 717.02 \\
Quintal) & $(94.55 \%)$ & $(48.92 \%)$ & $(68.41 \%)$ \\
\hline
\end{tabular}

Sources: Field Survey 2016-17.

Note: Figure in parenthesis is in percentage to total production.

\section{Marketing of Vegetables}

The various routes through which the commodities reach the final Consumer is known as marketing channels. The length of channels, routes, and intermediaries differs from vegetables to vegetables and also depends on the quantity, nature, and degree of specialization in production. It was observed that there exist three marketing channels in the study area which are:

Channel I: Producer - Consumer.

Channel II: Producer - Retailer (Village traders) Consumers.

Channel III: Producer - Wholesaler (Village agents/ traders)-Consumers.

In Channel I, there is a direct marketing of vegetables between the farmers and the consumers. The second Channel consists of the retailers who act as a middleman between the producer and the consumers. In the Channel III the Wholesaler purchases the goods from the farmers and sell it to the retailer who in turn sales it to the ultimate consumers.

\section{Disposal Pattern of Vegetables}

The disposal pattern shows how the goods (vegetables) are being disposed of through various channels. Different vegetables follow different channels through which they are disposed of from the Producers. The collective disposal pattern of Cabbage, Beans, and Potato is shown in table 3.

In the disposal patter of Cabbage, the Channel III is the most preferred channel where $98.01 \%$ of the Cabbage was disposed of by the Producer to the Wholesaler. Channel III is also the most preferred channel in the marketing of Potato, where $40.10 \%$ 
was disposed of. Channel III is non-existence in the marketing of Beans. It is being disposed of through Channel I and Channel II where Channel I disposes $81.27 \%$, which is direct marketing to the consumers. Channel I plays a very minimal role in Cabbage and Potato marketing.

Table 3: Disposal pattern of Vegetables through the different marketing Channels in Phek district: (in Quintal)

\begin{tabular}{lllll}
\hline \multirow{2}{*}{$\begin{array}{l}\text { Marketing } \\
\text { Channels }\end{array}$} & Channel & \multicolumn{3}{c}{ Quantity of Sold (in } \\
Quintal)
\end{tabular}

Source: Field Survey 2016-2017.

\section{Marketing Cost of Vegetables, Marketing Margin, and Price Spread}

Marketing margin depicts the marking efficiency and inefficiency; it includes the various costs of intermediaries and the profits of intermediaries earned in the process of transfer of goods from the Producer to the Consumer. The higher and larger marketing margin of the intermediaries indicates marketing inefficiency. Marketing Cost of Vegetables, Marketing Margin, and Price Spread is shown in table 4. In Channel I, it was found that the costs involved are the labour cost and the packing cost, which differs from vegetables to vegetables. The total cost of marketing is $7.10 \%$ for Cabbage, $1.01 \%$ for Beans, and $2.58 \%$ for Potato in terms of consumer rupee. The Net price received by farmers is $92.90 \%$ of consumer rupee for the marketing of Cabbage, $98.99 \%$ on Beans and 97.41 $\%$ on Potato, and there is no price spread in Chanel I. In Channel II the total overall marketing cost was $23.75 \%$ of consumer price for the marketing of Cabbage, $6.81 \%$ for Beans and $17.75 \%$ for Potato. The Net price received by the Producer in terms of consumer rupee was $54.13 \%$ on Cabbage marketing, $70.32 \%$ on Beans marketing and 62.17 for Potato marketing. The net margin of the retailers was $21.94 \%$ on Cabbage, $22.86 \%$ on Beans, and $20.08 \%$ on Potato. The price spread on Cabbage was $40 \%$ of the consumer rupee, $28.89 \%$ on Beans, and $28.57 \%$ on Potato. In channel III the Wholesaler and retailers act as an intermediary in the marketing of Cabbage and Potato. The overall marketing cost in Channel III was $25.27 \%$ of the consumer price in the marketing of Cabbage and $19.03 \%$ on the marketing of Potato. The Channel III observes the highest

Table 4: Marketing Efficiency Index of vegetable (₹/Total Quantity Sold)

\begin{tabular}{lllllllll}
\hline Particulars & \multicolumn{7}{c}{ Study Area, Phek District, Nagaland } \\
\cline { 2 - 9 } & \multicolumn{7}{c}{ Channel I } & \multicolumn{3}{c}{ Channel II } & \multicolumn{2}{c}{ Channel III } \\
\cline { 2 - 9 } & Cabbage & Beans & Potato & Cabbage & Beans & Potato & Cabbage & Potato \\
\hline Producers Net Price & 120,300 & 399165 & 533980 & 161300 & 84020 & 537085 & 10617360 & 541740 \\
& $(92.90)$ & $(98.99)$ & $(97.42)$ & $(54.31)$ & $(71.11)$ & $(62.17)$ & $(28.89)$ & $(41.87)$ \\
Marketing Cost & $9200(7.10)$ & $4070(1.01)$ & 14150 & 70550 & $8140(6.81)$ & 153335 & $8977984(25.27)$ & 246210 \\
& & & $(2.58)$ & $(23.75)$ & & $(17.75)$ & & $(19.03)$ \\
Marketing Margin & - & - & - & 65150 & 27315 & 173415 & 13718104 & 505800 \\
Value added by & 9200 & 4070 & 14150 & 135700 & 35455 & 326750 & 24905640 & 752010 \\
Marketing system & & & & & & & & \\
Consumer Price & 129500 & 403235 & 548130 & 297000 & 119475 & 326750 & 35523000 & 752010 \\
Price Spread & - & - & - & 118800 & 34515 & 246810 & 23682000 & 661250 \\
& & & & $(40.00)$ & $(28.89)$ & $(28.57)$ & $(66.67)$ & $(51.11)$ \\
\hline MARKETING EFFICIENCY & & & & & & \\
\hline Shepherd's Method & 14.08 & 99.07 & 38.74 & 4.21 & 14.68 & 5.63 & 3.96 & 5.25 \\
Acharya - Agarwal & 13.08 & 98.07 & 37.74 & 1.19 & 2.37 & 1.64 & 0.43 & 0.72 \\
Method & & & & & & & \\
\hline
\end{tabular}

Sources: As per findings based on field survey 2016-2017; Note: Figure in parenthesis is in percentage to total consumer rupee. 
marketing cost as compared to other channels. The Net price received by Producers in channel III was $28.89 \%$ of the consumer price on the marketing of Cabbage and $41.87 \%$ on Potato. In channel III the price spread in the marketing of Cabbage was 66.675 of the consumer rupee and $51.11 \%$ on Potato.

\section{Marketing Efficiency}

The Marketing efficiency index for Cabbage Marketing in Channel I through Shepherd method was 14.08, 4.21 for channel II and 3.46 for channel III; which indicates that Channel I is the most efficient marketing Channel in the marketing of Channel I. Similarly Acharya-Agarwal methods show a higher marketing efficiency on Channel I, i.e., 13.08 on the marketing of Cabbage.

In the marketing of Beans where there are only two channels involved both Shepherds and AcharyaAgarwal methods indicates a higher efficiency on the Channel I with marketing efficiency ratio of 99.07 and 98.07 respectively.

Shepherds method and Acharya-Agarwal methods both gives a higher marketing efficiency ratio to channel I in the marketing of Potato; the ratio were 38.21 and 37.74 respectively indicating that the efficient marketing Channel is Channel I. The channel I in all the vegetables involves the least marketing cost and higher Net price for the Producer and there is no price spread between the Producer and the Consumer. Hence the Channel I is the most efficient marketing channel for the marketing of Vegetables in Phek district, Nagaland.

\section{CONCLUSION AND SUGGESTION}

From the discussion it was found that marketable Surplus of Cabbage is higher than that of other vegetables. Three marketing channels were existence in the district for the disposal of vegetables except for Beans only two channels were observed. From the marketing efficiency method of Shepherds and Acharya-Agarwal the Channel I was found to be the most efficient marketing Channel as such steps should be taken and encouraged to improve and expand the Channel I. However, vegetable production and marketing are not free from problems. Thus, to remove various constraints faced in the production and marketing certain policy suggestions are laid down here.
1. The foremost problem faced by the farmers was the unavailability of cheap, subsidized disease resistance seeds and saplings. Thus, it is suggested that adequate supply of subsidized disease resistance seeds and sapling be provided to the farmers by the concerned department to reduce the cost of producing for the farmers. Since on the producing side, the cost shoots up from the purchase of seeds and sampling for cultivation.

2. Most of the farmers did not receive training and workshops due to irregularity of such programmes therefore regular workshops, seminars, and training at regular intervals should be organized so that farmers are aware of various efficient methods of vegetable cultivation.

3. The maximum marketing costs of the intermediaries are transportation costs which are expensive due to poor road conditions. Therefore, road connectivity should be well maintained so that transportation cost and the marketing cost are minimized.

4. In the study, only a few farmers availed credit facilities from the credit institutions. Therefore, easy availability of credit facilities should be made for the farmers which in turn will increase production.

5. There is a lack of organized regulated market and lack of market information. Hence, the establishment of more organized regulated market is the need of the hour where the farmers get all the market information with regard to the price and demand of vegetables.

6. Unavailability of Storage facilities is a major problem which hampers the production and marketing of vegetables as such, the construction and facilities of cold storage will reduce the pre and post-harvest losses.

7. The marketing cost especially in Channel II and Channel III increases due to multiple taxes in the process of transporting and marketing of vegetables which should be addressed so as not to discourage the Producer and also to reduce the marketing cost and the price spread. 
8. Lastly, it was observed that Channel I is the most efficient vegetable marketing channel as such steps should be taken to improve, encourage and expand Channel I by opening more local agricultural markets where the farmers can sell off the vegetables directly to the consumers.

In conclusion, it was observed that the district has a favourable climatic condition which is conducive for the production of vegetables. The district can play a major role in the self-sufficiency and revenue generation for the district and for the state if the various constraints in the production and marketing of vegetables are taken care off.

\section{REFERENCES}

Acharya, S.S. and Agarwal, N.L. 2014. Agricultural Marketing in India $\left(5^{\text {th }} \mathrm{Edn}\right)$ Oxford \& IBH Publishing Co. Pvt. Ltd. New Delhi.

Dastagiri, M.B., Chand, R.T.K., Immanuelraj, C.V. Hanumanthaiah, P. Paramsivam, R.S. Sidhu, M. Sudha, Mandal, S., Singh, B. Chand, K. and Kumar, B.G. 2013. Indian Vegetables: Production Trends, Marketing Efficiency and Export Competitiveness. Journal of Agriculture and Forestry, 1(1): 1-11.

Gupta, S.P. and Rathore, N.S. 1998. Marketing of Vegetables in Raipur District of Chhattisgarh State: An Economic Analysis", Indian Journal of Agriculture Economics, 53(3): 393.
Gunwant, V.K., Hussain, M., Purohit, R.C., Ali, Syed Mohd. F. and Rana, D. 2012. A comparative study of production and marketing pratices of vegetables in Nainital and U.S. Nagar district of State of Uttarakhand, India. International Journal of Advances in computing and information Technology, pp. 569-578.

Jadav, K.S., Leua, A.K. and Darji, V.B. 2011. 'Economic analysis of supply chain of fresh potato in middle Gujarat", Indian J. Agric. Res., 45(4): 266- 274.

Khalon, A.S. and George, M.V. 1985. Agricultural Marketing and Price Policies, Allied Publishers Private Ltd., Bombay.

Kolter, P.G. Armstrong. 2003. Principle of Marketing. 10 $10^{\text {th }}$ Edition, Hall of India Pvt. Ltd., New Delhi, pp. 5-12.

Kaul, G.L. 1997. Horticulture in India: Production, Marketing and Processing", Indian Journal of Agricultural Economics, 52(3).

Shepherd, G.S. 1965. Marketing Farm Products - Economic Analysis, Towa, State university Press, Ames Iowa, U.S.A.

Vasant P. Gandhi and Namboodiri, N.V. 2004. Marketing of Fruits and Vegetables in India: A Study Covering the Ahmedabad, Chennai and Kolkata Markets.

Wadhwani, M.K. and Bhogal, T.S. 2003. Price Behaviour of Seasonal Vegetables in Uttar Pradesh - A Comparative Study of Western (Plain) and Hill Regions. SAARC J. of Agric., 1. 